research and possibly search for new parameters of the ILP activity are needed.

Disclosure of Interests: None declared

DOI: 10.1136/annrheumdis-2019-eular.3735

\section{FRI0589 IS THERE AN OVERLAP OF ANTINEUTROPHIL CYTOPLASMIC ANTIBODY-ASSOCIATED VASCULITIDES WITH IGG4-RELATED DISEASE OR NOT?}

Abdulsamet Erden, Ertuğrul Çağrı Bölek, Gözde Kübra Yardımcı, Şule Apraş Bilgen, Omer Karadag, Hacettepe University Vasculitis Centre, Hacettepe University Vasculitis Centre. Hacettepe University Vasculitis Center, Ankara, Turkey

Background: Pseudotumor orbita, pachymeningitis, periaortitis could be seen in both ANCA-associated vasculitis and IgG4-RD. Sometimes it may be difficult to differentiate these two entities. The co-occurrence/concurrence of Antineutrophil cytoplasmic antibody (ANCA)-associated vasculitides (AAV) and lgG4-related disease (IgG4-RD) was recently published by a collaborative EUVAS group [1].

Objectives: Firstly, we aimed to investigate ANCA positivity of our IGG4$\mathrm{RD}$ cohort. Secondly, a literature review of co-occurrence/concurrence of AAV and IgG4-RD was done.

Methods: Data of totally 62 patients with IgG4-RD in Hacettepe Vasculitis Center Database was used. Patients were diagnosed with IgG4-RD according to comprehensive diagnostic criteria [2]. Dataset of patients including demographic data, clinical characteristics, and imaging and laboratory findings of IgG4-RD was re-evaluated in terms of AAV and ANCA test.

At next step, we performed a systematic literature review of the PUBMED database covering the time period until April 2018. Relevant publications were searched using the MeSH terms "IgG4-related disease and Eosinophilic Granulomatosis with Polyangiitis", "IgG4-related disease and Anti-Neutrophil Cytoplasmic Antibody-Associated Vasculitis" and "IgG4related disease and Granulomatosis with Polyangiitis".

Results: Totally $29(46.7 \%)$ of our patients had ANCA results. Out of 29 patients $15(51.7 \%)$ were considered as probable, $10(34.5 \%)$ as definite and 4 as possible (13.8\%) for IgG4-RD. Three (10.3\%) of these patients had ANCA positivity. All of these ANCA titers were in low degree positivity (MPO-ANCA 1/100, MPO-ANCA 1/32 and PR3 ANCA 1/100). These three patients didn't have any findings of vasculitis and didn't have granuloma in their biopsy. When we evaluate these three patients with regards to meeting the Ig G4- RD criteria, 1 was definite, 1 was probable and 1 was possible.

In literature review, we found 17 cases that having both features of IgG4-RD and AAV (Table). These cases were re-evaluated according to the 'Comprehensive Diagnostic Criteria for IgG4-RD'. Diagnoses of IgG4$\mathrm{RD}$ were definite in 11 cases $(64.7 \%)$, probable in 2 cases $(11.8 \%)$ and possible in 4 cases (23.5\%). ANCA were positive in 15 of 17 patients (88\%). ANCA were directed against proteinase 3 (PR3-ANCA) in 6 patients and were directed against myeloperoxidase (MPO-ANCA) in 5 patients. Other four cases had both MPO-ANCA and PR3-ANCA. All PR3-ANCA positive cases have high titers of ANCA, whereas only one MPO-ANCA positive case has high titers of ANCA.

Conclusion: None of our IgG4-RD patients have any overlap with ANCAassociated vasculitis. Only in 3 patients (10.3\%), ANCA positivity was detected without any histopathologic evidence. Just two patients of literature review, seemed to be full compatible with both diseases. Even though ANCA-associated vasculitis and IgG4-RD share clinical features, we think this might be as co-occurrence instead of a histopathologic link.

\section{REFERENCES:}

[1] Danlos, FX. Autoimmun Rev, 2017.

[2] Umehara, H. Mod Rheumatol, 2012.

Disclosure of Interests: None declared

DOI: 10.1136/annrheumdis-2019-eular.6130

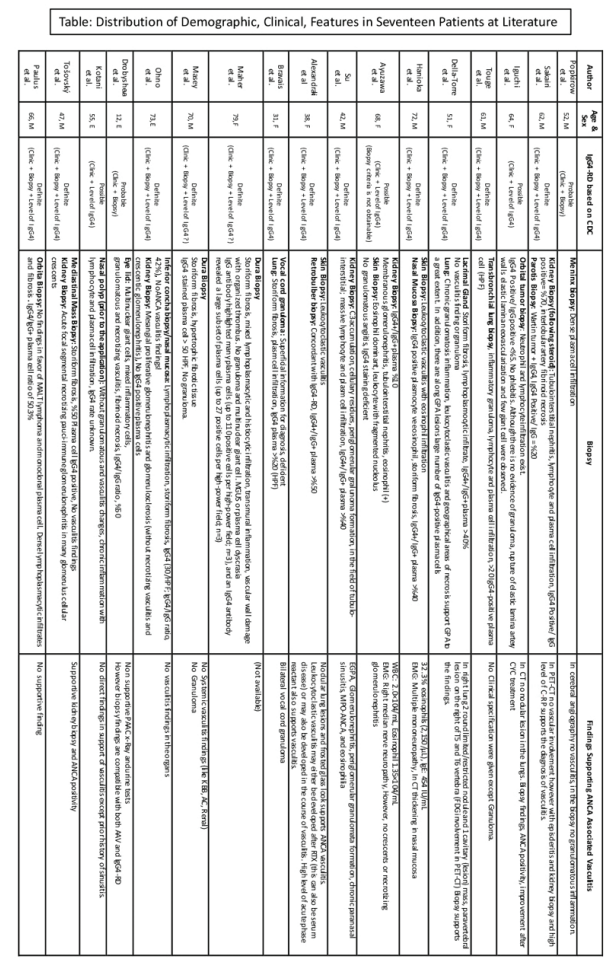

\section{\begin{tabular}{|l|l|l|l|}
\hline FRI0590 UVITIS SECONDARY TO CHECKPOINT INHIBITORS \\
\hline
\end{tabular}}

\section{JAVIER GARCÍA, Eugenio Perez-Blazquez. HOSPITAL 12 DE OCTUBRE,} MADRID, Spain

Background: The introduction of immunotherapy (immune checkpoint inhibitors, $\mathrm{ICl}$ ) has led to a revolution in oncological treatments. The inhibitors of CTLA4 (ipilimumab), of PD1 (pembrolizumab, nivolumab) and of the ligand of PD1 (atezolizumab, avelumab, durvalumab) regulate $T$ activation and its effector function, being effective for the treatment of various types of cancer $^{1}$. However, this effect leads to a series of immune-mediated adverse events, among which uveitis of autoimmune mechanism have been described in about $1 \%$ of treatments ${ }^{2}$.

Objectives: Methods: descriptive study of retrospective review of the cases of a tertiary hospital with about 1000 treatments between the beginning of 2014 and the end of 2018 .

Results: A series of 4 cases of uveitis of autoimmune origin associated with $\mathrm{ICl}$ is presented (see table). The series described has characteristics similar to the information previously reported in the literature ${ }^{2}$, with an incidence of around $0.4 \%$, according to the previously described, with frequencies of ocular toxicity around $1 \%$, being the uveitis is the most frequent form of presentation. The time of presentation of uveitis since the beginning of treatment has been in all cases in the first 6 months. The forms of presentation described before, ranges from anterior uveitis (AU) to panuveitis and often papilledema, usually bilateral, as are all those described in our series. In addition, $50 \%$ are $\mathrm{AU}$ (grade 2) and the other $50 \%$ panuveitis with papilledema (grade 3 ). In all the cases described, treatment was interrupted, a half it could be reintroduced without recurrence of uveitis. All the patients received topical treatment, the more severe systemic corticosteroids at doses of $0.5-1 \mathrm{mg} / \mathrm{kg}$ in accordance with the recommendations. The final prognosis was good, with preservation of VA in all cases, and topical and systemic treatment could be withdrawn in all patients. A patient treated with Ipilimumab presented synechiae as a complication. 


\begin{tabular}{|c|c|c|c|c|c|c|c|c|c|}
\hline & ONCO diagnosis & ONCO treatment & time & OPH diagnosis & $\begin{array}{l}\text { Toxicity } \\
\text { (G) }\end{array}$ & OPH tretament & $\mathrm{ICI}$ withdrawal & Prognosis & $\begin{array}{c}\text { Other } \\
\text { toxicities }\end{array}$ \\
\hline $\begin{array}{l}0^{x} \\
79\end{array}$ & $\begin{array}{l}\text { Melanoma BRAF wt+ } \\
\text { retroperitonealmtt }\end{array}$ & $\begin{array}{l}\text { Pembrolizumab x7 } \\
\text { Ipilimumab x2 }\end{array}$ & $\begin{array}{l}6 \mathrm{~m} \\
6 \mathrm{w}\end{array}$ & $\begin{array}{l}\text { Bilateral AU with } \\
\text { synechia }\end{array}$ & 2 & $\begin{array}{c}\text { Prednisone } 1 \\
\mathrm{mg} / \mathrm{kg} \\
+ \\
\text { Topical }\end{array}$ & Temporal & $\begin{array}{c}\text { No inflammation without } \\
\text { treatment } \\
\text { VA Preserved } \\
\text { Synechia }\end{array}$ & $\begin{array}{l}\text { Transaminitis } \\
\text { G2 } \\
\text { Asthenia G2 }\end{array}$ \\
\hline $\begin{array}{l}\sigma^{\pi} \\
85\end{array}$ & $\begin{array}{c}\text { Cáncer de vejiga localizado } \\
\text { avanzado }\end{array}$ & Atelizumab x7 & $5 \mathrm{~m}$ & Bilateral AU & 2 & Topical & Definitive & $\begin{array}{c}\text { No inflammation without } \\
\text { treatment } \\
\text { VA Preserved }\end{array}$ & $\begin{array}{c}\text { PMR G2 } \\
\text { Thyroiditis G1 } \\
\text { Transaminitis } \\
\text { G1 } \\
\text { Mucositis G1 }\end{array}$ \\
\hline $\begin{array}{l}0^{x} \\
45\end{array}$ & $\begin{array}{l}\text { Melanoma BRAF mutant } \\
\text { (retropectoral mass) }\end{array}$ & Pembrolizumab x5 & $4 m$ & $\begin{array}{l}\text { Bilateral Panuveitis with } \\
\text { synechia } \\
+ \text { papilledema }\end{array}$ & 3 & $\begin{array}{l}\text { Prednisone } 0,5 \\
\text { mg/kg } \\
+ \text { topical }\end{array}$ & Definitive & $\begin{array}{c}\text { No inflammation without } \\
\text { treatament } \\
\text { VA Preserved }\end{array}$ & None \\
\hline $\begin{array}{l}0^{x} \\
47\end{array}$ & $\begin{array}{c}\text { Melanoma BRAF wt (abdomial } \\
\text { mass } \\
\text { +peritoneal } \mathrm{mtt} \\
+ \text { adrenal } \mathrm{mtt} \text { ) }\end{array}$ & $\begin{array}{l}\text { Nivolumab x2 } \\
\text { Ipilimumab x1 }\end{array}$ & $\begin{array}{l}2 m \\
1 m\end{array}$ & $\begin{array}{l}\text { Bilateral Panuveitis with } \\
\text { synechia } \\
+ \text { papilledema }\end{array}$ & 3 & $\begin{array}{l}\text { Prednisone } 0,5 \\
\text { mg/kg } \\
+ \text { topical }\end{array}$ & $\begin{array}{l}\text { Nivolumab } \\
\text { temporal } \\
\text { Ipilimumab } \\
\text { definitive }\end{array}$ & $\begin{array}{c}\text { No inflammation without } \\
\text { treatament } \\
\text { VA Preserved }\end{array}$ & $\begin{array}{l}\text { Rash G1 } \\
\text { Pruritus G1 } \\
\text { Vitíligo }\end{array}$ \\
\hline
\end{tabular}

Conclusion: Uveitis is an infrequent, although potentially serious, immunemediated side effect of $\mathrm{ICl}$. Early recognition, discarding other causes of uveitis, particularly the masquerade syndrome, and early intervention are key to a good prognosis. The collaboration between the oncology teams and the ocular inflammation units must be close to establish the correct diagnosis and treatment, as well as to decide individually on the reintroduction or not of the oncological treatment. The implementation of registers on the adverse effects of these drugs can help to dimension the problem more accurately.

\section{REFERENCES:}

[1] Calabrese LH, Calabrese C, Capelli, LC. Rheumatic immune-related adverse events from cancer immunotherapy. Nat Rev Rheumatol. 2018 Oct;14(10):569-579.

[2] Dalvin LA, Shields CL, Orloff M, Sato T, Shields JA. Checkpoint inhibitor immune therapy: Systemic Indications and Ophthalmic Side Effects. Retina. 2018 Jun;38(6):1063-1078.

Disclosure of Interests: None declared

DOI: 10.1136/annrheumdis-2019-eular.5473

\section{FRI0591 RHEUMATIC IMMUNE-RELATED ADVERSE EVENTS ASSOCIATED WITH TREATMENT WITH IMMUNE CHECKPOINT INHIBITORS: A CASE SERIES FROM TWO REFERRAL CENTRES}

Sebastian C. Rodriguez-García', David Lobo ${ }^{2}$, Raul Castellanos-Moreira ${ }^{1}$, Ana Milena Millán Arciniegas ${ }^{2}$, Roberto Gumucio ${ }^{1}$, Ana Laiz ${ }^{2}$, Virginia Ruiz-Esquide ${ }^{1}$ Berta Magallares ${ }^{2}$, Cesar Díaz-Torné2 ${ }^{2}$, Patricia Moya ${ }^{2}$, Ivan Castellví ${ }^{2}$, Hector Corominas ${ }^{2}$, Jose A. Gómez-Puerta ${ }^{1}{ }^{1}$ Hospital Clínic de Barcelona, Rheumatology, Barcelona, Spain; ${ }^{2}$ Hospital de la Santa Creu i Sant Pau, Rheumatology, Barcelona, Spain

Background: Immune checkpoint inhibitors (ICI) against CTLA-4 or PD-1/ PD-L1 improve the survival of patients with advanced malignancies including melanoma, lung cancer among other tumours. Because of its mechanism of action, $\mathrm{ICl}$ are prone to produce different immune-related adverse events (irAEs), including musculo-skeletal manifestations.

Objectives: Our aim was to describe the experience with rheumatic irAEs in two tertiary centres.

Methods: All adult patients referred to the Rheumatology department from 2015 to 2018 because of the onset of musculo-skeletal symptoms following treatment with an $\mathrm{ICl}$ were included. Data collected comprised demographic features as well as $\mathrm{ICl}$ indication and type, history of rheumatic disease, disease manifestations at irAE onset, laboratory tests, ultrasound findings and treatment. Diagnostic and treatment approach was done according clinical judgment and in a daily clinical practice setting.

Results: 20 patients were included, $50 \%$ female, with a mean age of 61,5 years (range 32-83). The indication for $\mathrm{ICl}$ was melanoma in 10 cases, lung cancer in 5, urothelial neoplasia in 2 and squamous skin, breast and head and neck cancer in 1 case each. Pembrolizumab was the most used $\mathrm{ICl}$ accounting for 9 cases (1 combined with epacadostat), 8 patients were treated with Nivolumab (4 combined with Ipilimumab), 2 wit Atezolizumab (1 combined with Ibatasertib) and 1 Ipilimumab in monotherapy.

A history of previous rheumatic disease was reported in 8 patients (1 seropositive RA, 1 Spondyloarthritis, 1 SLE, 1 gout, 1 chondrocalcinosis, 1 fibromyalgia, 1 De Quervain tendinitis, 1 hand osteoarthritis) and 1 had psoriasis.
The most frequent irAE presentation was arthritis with 8 cases $(40 \%)$, arthralgia in 4 cases $(20 \%), 1$ case of myalgia, 2 presented PMR-like symptoms, 1 tenosynovitis and 2 paraesthesia (1 with associated dysesthesia).

After assessment, 7 patients were diagnosed as undifferentiated arthritis, 1 leukocytoclastic vasculitis, 1 small-vessel vasculitis, 2 psoriatic-like arthritis, 1 tenosynovitis, 2 PMR and 6 were classified as having non-inflammatory symptoms.

Antibody status was analyzed in 16 patients. Anticitrullinated-peptide antibodies, rheumatoid factor and HLA B27 were negative in all cases (except for 1 patient with seropositive RA), ANAs were positive in 4 (including 1 patient with previous SLE) but without any specificities (i.e. ENAs) and ANCA were negative in one case with small-vessel vasculitis. Ultrasound assessment was performed in 6 patients, 3 presented synovial hypertrophy with positive power Doppler (1 with tenosynovitis associated), 1 peritendinous fluid collection, 1 elbow joint effusion and 1 bilateral supraspinatus calcified tendinopathy.

Most patients were treated with glucocorticoids $12(60 \%)$ and NSAID 6 $(30 \%)$ and only 3 patients had to discontinue ICI treatment due to irAEs. Conclusion: Our results were in line with previous studies showing that musculo-skeletal irAEs associated to $\mathrm{ICl}$ may present as a flare of a previous known rheumatic disease or as a de novo symptom. Most patients presented with asymmetric mono or oligoarthritis having a good response to GC and NSAID without the need of adding DMARD or withdraw of $\mathrm{ICl}$ therapy..

Disclosure of Interests: Sebastian C Rodriguez-García: None declared, DAVID LOBO: None declared, Raul Castellanos-Moreira Speakers bureau: MSD, Lilly, Ana Milena Millán Arciniegas: None declared, Roberto Gumucio: None declared, Ana Laiz Consultant for: Lilly, Novartis, AbbVvie, MSD, UCB and Janssen, Speakers bureau: Lilly, Novartis, Abvvie, MSD, UCB and Janssen, Virginia Ruiz-Esquide Speakers bureau: Sanofi, Lilly, MSD, Berta Magallares: None declared, Cesar Díaz-Torné: None declared, Patricia Moya: None declared, Ivan Castellví Consultant for: I received fees less than 5000USD as a consultant for Kern and Actelion, Paid instructor for: I received fees less than 2000USD as a instructor for Boehringer -Ingelheim, Novartis and Gebro, Speakers bureau: ND, Hector Corominas: None declared, Jose A. Gómez-Puerta Consultant for: Pfizer, Roche, Speakers bureau: Abbvie, BMS, Janssen, MSD, Pfizer, Roche DOI: 10.1136/annrheumdis-2019-eular.301

\section{FRI0592 CLINICAL CHARACTERISTICS OF OLDER AGE-ONSET BEHÇET SYNDROME PATIENTS}

Gul Guzelant Ozkose ${ }^{1}$, Yilmaz Ozyazgan², Cem Mat ${ }^{3}$, Vedat Hamuryudan ${ }^{1}$, Hasan Yazici ${ }^{1}$, Emire Seyahi ${ }^{1} .{ }^{1}$ Istanbul University-Cerrahpasa, Medical Faculty of Cerrahpasa, Internal Medicine, Division of Rheumatology, Istanbul, Turkey; ${ }^{2}$ Istanbul University-Cerrahpasa, Medical Faculty of Cerrahpasa, Ophthalmology, Istanbul, Turkey, ${ }^{3}$ Istanbul University-Cerrahpasa, Medical Faculty of Cerrahpasa, Dermatology, Istanbul, Turkey

Background: The usual onset of Behçet syndrome (BS) is in the 3. decade. Older age-onset defined as fulfilling the ISG criteria after 40 years of age is rare. One study from our center had reported the severity of eye disease was not different between early onset ( $\leq 24$ years) and late onset ( $\geq 25$ years) group. (1). While there is ambiguity in the definition of older onset, a few case series $(2,3)$ coming mostly from ophthalmology or dermatology settings describe a similar or less severe clinical picture among late onset patients (pts) compared to early onset. Objectives: To evaluate clinical characteristics of older onset pts and to compare them with classic onset pts. 